\title{
As invalidades do Ato Administrativo no Lançamento Tributário
}

\section{INVALIDITIES AS THE LAUNCH IN TAX Administration ACt}

Patrícia Toledo de Campos *

Reinaldo de Oliveira Bruniera **

Resumo: O texto analisa o conceito do vocábulo "lançamento", levando em conta a divergência existente sobre esse ser um ato administrativo, ato jurídico administrativo, procedimento administrativo, ou ambos. Aborda a questão do instituto da revogação não ser admitido no lançamento tributário. Enfatiza a hipótese de que na condição de ato, o lançamento tributário se sujeita às lições previstas no ramo do Direito Administrativo, especificamente no que concerne à aplicação da teoria dos atos administrativos. Também, irá se analisar a possibilidade da invalidação do lançamento tributário decorrente de vícios, com base na tradicional diferenciação entre atos nulos e anuláveis verificando o cabimento de revisão ou alteração do lançamento pelo fisco.

Palavras-Chave: Lançamento tributário; Ato jurídico administrativo; Revogação; Regime jurídico; Invalidades.

Abstract: The paper analyzes the concept of the word "launch", taking into account the divergence about this being an administrative, legal administrative act, administrative procedure, or both. Addresses the issue of revocation of the institute not be admitted to the tax assessment. Emphasizes the hypothesis that the condition of the act, the tax assessment is subject to the lessons provided in the field of administrative law, specifically regarding the application of the theory of administrative acts. Also, will examine the possibility of invalidation of the tax assessment resulting from addictions, based on the traditional distinction between void and voidable acts verifying the appropriateness of revising or amending the launch by the tax authorities.

Keywords: Release tax, legal administrative act; Revocation; legal regime; invalidities.

** Pós-graduando em Direito do Estado pela Universidade Estadual de Londrina (UEL). E-mail: reinaldo bruniera @,hotmail.com

* Pós-graduanda em Direito do Estado pela Universidade Estadual de Londrina (UEL). E-mail: patty toledo_campos a, hotmail.com 


\section{INTRODUÇÃO}

Animada pelas elaborações continentais europeias que discutiam sobre a eficácia declaratória ou constitutiva do lançamento, a doutrina brasileira ingressou no debate entendendo majoritariamente pela eficácia declaratória do lançamento, o que levou para segundo plano tema importantíssimo para o estudo do direito tributário, que é a análise do lançamento tributário como um ato jurídico administrativo, ato administrativo ou procedimento administrativo.

O presente trabalho busca apresentar a temática da demarcação conceitual do vocábulo "lançamento", de grande importância no contexto social e jurídico. $\mathrm{O}$ estudo será realizado com base na divergência doutrinária que existe sobre a questão do lançamento ser um ato, procedimento, ou ambos.

Serão apresentados os conceitos de lançamento tributário e ato administrativo. Também serão abordados os diferentes posicionamentos sobre a existência de requisitos de validade para realização de atos administrativos.

A seguir, será exposto o regime jurídico do ato administrativo do lançamento tributário com foco na distinção entre nulidade e anulabilidade, análise esta primordial para melhor compreensão do tema proposto.

A partir do entendimento de como se constitui o lançamento tributário, será abordada a teoria geral dos atos administrativos com ênfase nos temas: revogação e invalidade.

Neste sentido, discorrer-se-á sobre a possibilidade de ocorrência de erro de fato e erro de direito, assunto este objeto de grande divergência doutrinária.

Por fim, será apresentado o posicionamento do Superior Tribunal de Justiça analisando a questão da nulidade e anulabilidade do lançamento tributário com base na teoria dos atos administrativos, bem como outras explanações cuja compreensão torna-se primordial ao presente trabalho.

\section{CONCEITOS DE LANÇAMENTO TRIBUTÁRIO}

O lançamento tributário é imprescindível para que o sujeito ativo, isto é o Fisco, exercite a cobrança do valor devido com o intuito de satisfazer o respectivo crédito, primeiramente, em sede administrativa, para depois, caso não logre êxito, exerça a cobrança por meio de ação judicial que precede de uma providência formal que é a inscrição do crédito tributário inadimplido em dívida ativa. MACHADO (2011, p.174) define lançamento tributário como: 
“[...] procedimento administrativo tendente a verificar a ocorrência do fato gerador da obrigação correspondente, identificar o seu sujeito passivo, determinar a matéria tributável e calcular ou por outra forma definir o montante do crédito tributário, aplicando, se for o caso, a penalidade cabível”.

Nesse mesmo sentido, FÜHRER sustenta (2001, p. 58), embasado no que está contido no Código Tributário Nacional, que lançamento:

"É o procedimento administrativo vinculado que verifica a ocorrência do fato gerador, identifica o sujeito passivo da obrigação tributária, determina a matéria tributável, aponta o montante de crédito e aplica, se for o caso, a penalidade cabível (ar.142)".

Afirma o referido autor que o lançamento é constitutivo do crédito tributário, mas que esse seria apenas declaratório da obrigação e que, portanto, seus efeitos retroagiriam ao tempo da ocorrência do fato gerador. Argumenta ainda, que a lei aplicável é aquela da data da ocorrência do fato gerador (art. 143), mas que em relação à aplicação da penalidade deve impor-se o princípio da retroatividade da lei mais benéfica (art. 106). Sustenta, também, ser o lançamento ato privativo da Fazenda Pública credora da obrigação e obrigatório para a autoridade tributária, sob pena de responsabilidade funcional.

Entretanto, data vênia, tais posicionamentos não são os mais adequados por conterem improbidades. Em que pese a definição de lançamento estar contida no artigo 142 do Código Tributário Nacional, este não deve ser interpretado literalmente, sob pena de se cometer equívocos. A respeito, com muita acuidade, escreve CARVALHO (2011, p.454):

"Decididamente, é problemática a tese do lançamento como procedimento administrativo, lamentando-se que o legislador do Código haja inserido esse conceito no dispositivo do artigo 142, agravando a incoerência com permitir que o agente público possa vir a propor a aplicação de penalidades, nas hipóteses de descumprimento das prestações tributárias".

Partindo do entendimento que lançamento tributário é um ato jurídico administrativo e não um procedimento, com muita veemência escreve CARVALHO (2011, p.464) definindo lançamento:

"Lançamento tributário é o ato jurídico administrativo, da categoria dos simples, constitutivos e vinculados, mediante o qual se insere na ordem 
jurídica brasileira u'a norma individual e concreta, que tem como antecedente o fato jurídico tributário e, como consequente, a formalização do vínculo obrigacional, pela individualização dos sujeitos ativo e passivo, a determinação do objeto da prestação, formado pela base de cálculo e correspondente alíquota, bem como pelo estabelecimento dos termos espaçotemporais em que o crédito há de ser exigido".

O referido autor explica que o lançamento muitas vezes consiste no resultado de um procedimento, mas que com ele não deve se confundir. Explica que o procedimento não é imprescindível para o lançamento que poderia ocorrer com um ato isolado e independente. Também faz importante ressalva da adoção do lançamento como ato jurídico administrativo citando o ilustre Fagundes (CARVALHO, 2011, p.465):

“[...] vem ao pensamento distinção de relevo, que M. Seabra Fagundes expõe com muita nitidez, ao lembrar que os atos administrativos podem ser ou não jurídicos. Quando modificam situações jurídicas, como a nomeação de um funcionário, a expedição de um título de habilitação profissional, a imposição de multa etc., são atos administrativos jurídicos ou atos administrativos com efeitos jurídicos. Quando, porém, o ato praticado no exercício da administração não cria, modifica ou extingue direitos, é destituído de efeitos jurídicos, no sentido preciso da expressão. Será um ato administrativo sem efeito jurídico. É o que se dá quando a declaração de vontade não visa a produzir determinados efeitos, ficando aqueles dependentes de ato ulterior".

Outra incoerência que pode ser apontada diz respeito à afirmação contida no artigo 142 do Código Tributário Nacional de que o lançamento tributário seria "tendente a verificar a ocorrência do 'fato gerador"', eis que o legislador confundiu o ato de lançamento com eventuais ações emanadas pela autoridade que visem verificar a ocorrência ou não do fato jurídico tributário.

Com muita acuidade, delimita AMARO (2007, p.406) sobre o tema:

“[...] O lançamento pressupõe que todas as investigações eventualmente necessárias tenham sido feitas e que o fato gerador tenha sido identificado nos seus vários aspectos subjetivo, material, quantitativo, espacial, temporal, pois só com essa prévia identificação é que o tributo pode ser lançado".

Portanto, sinteticamente pode-se afirmar que quando o Fisco efetua o lançamento agindo de maneira ordinária, ou extraordinária (neste caso 
pode-se pensar como exemplo o contribuinte que preste informação deficiente ou deixe de presta-la), a função do lançamento tributário é de tornar certo e líquido o dever jurídico tributário para que o tributo possa ser cobrado administrativamente ou, caso o devedor não cumpra a obrigação, através do Poder Judiciário com a propositura da Execução Fiscal.

\section{ATO ADMINISTRATIVO, ATO JURÍDICO ADMINISTRA- TIVO OU PROCEDIMENTO?}

A lição do renomado jurista CARVALHO (2011, p.466) sugere o emprego com cautela da expressão "ato jurídico administrativo" para se referir aos atos jurídicos praticados pela Administração Pública no exercício de função administrativa como ocorre com o lançamento que possui efeitos de direito. Para o autor, no lançamento encontraríamos os requisitos de essência do gênero atos jurídicos, qual seja: agente capaz, objeto lícito, possível, determinado ou determinável, e forma prescrita ou não defesa em lei, bem como elementos específicos que são os motivos e a finalidade do ato. Conclui pela existência de cinco elementos integrativos na estrutura interior de todo ato jurídico administrativo, apresentada na teoria geral dos atos administrativos. São eles: a) motivo ou pressuposto; b) agente competente; c) forma prescrita em lei; d) objeto ou conteúdo; e) finalidade.

Entretanto, apesar de admitir que o lançamento possa ser um ato jurídico administrativo faz a ressalva que nem todo ato jurídico administrativo realiza a figura típica do lançamento tributário.

Realizadas essas ponderações, passaremos ao estudo do que vem a ser entendido por ato administrativo.

Não há definição legal para ato administrativo, existindo divergência na doutrina a respeito de seu conceito. Sua definição visa individualizar um determinado tipo de ato estatal, marcado por características antagônicas às dos atos civis e às dos atos típicos dos poderes Legislativo e Judiciário.

Para MELLO (2007, p.368), em sentido amplo, pode-se definir ato administrativo como:

"Declaração do Estado (ou de quem lhe faça as vezes- como, por exemplo, um concessionário de serviço público), no exercício de prerrogativas públicas, manifestada mediante providências jurídicas complementares da lei a título 
de lhe dar cumprimento, e sujeitas a controle de legitimidade por órgão jurisdicional."

Para o doutrinador JUSTEN FILHO (2011, p.351) ato administrativo é uma manifestação de vontade que exterioriza a pretensão de um sujeito dirigida com alguma finalidade, sendo composto por dois aspectos inconfundíveis na vontade que é "[...] a exteriorização física, consistente numa ação ou omissão" e o "[...] aspecto interno, volitivo, que é a causa da ação ou omissão".

Já MEIRELLES (2007, p. 145) define ato administrativo como:

"Toda manifestação unilateral de vontade da Administração Pública que, agindo nessa qualidade, tenha por fim imediato adquirir, resguardar, transferir, modifica, extinguir e declarar direitos, ou impor obrigações aos administrados ou a si própria."

No que tange aos requisitos de validade do ato administrativo existe forte divergência na doutrina quanto ao número de requisitos (ou pressupostos). Como o tema ainda não foi objeto de tratamento legislativo, cada autor acaba por elucidar o que entende por correto. De maneira geral, pode-se destacar a existência de duas correntes mais relevantes.

A primeira é denominada de clássica, sendo defendida por MEIRELLES, que se baseia no artigo $2^{\circ}$ da Lei $4.717 / 65$, segundo o qual:

"são nulos os atos lesivos ao patrimônio das entidades mencionadas no artigo anterior, nos casos de: a) incompetência; b) vício de forma; c) ilegalidade do objeto; d) inexistência dos motivos; e) desvio de finalidade".

De acordo com essa visão, os requisitos do ato administrativo são: a) competência; b) objeto; c) forma; d) motivo; e) finalidade. Deve-se destacar que objeto e motivo seriam requisitos discricionários por comportar margem de liberdade, entretanto, competência, forma e finalidade seriam requisitos vinculados.

A segunda é a denominada de corrente moderna cujo defensor é Celso Antônio Bandeira de Mello que defende a existência de seis pressupostos de validade: a) sujeito; b) motivo; c) requisitos procedimentais; d) finalidade; e) causa; f) formalização. Sujeito, requisitos procedimentais e causa seriam requisitos vinculados. Motivo, finalidade e formalização constituiriam requisitos discricionários. 
Segundo os renomados autores, com base na identificação dos requisitos do ato administrativo, seria possível precisar quais as patologias mais frequentes envolvendo a sua prática e indicar as consequências normativas delas decorrentes.

SOUZA (1950, p.228), ao escrever sobre o conceito jurídico de lançamento, dezesseis anos antes da divulgação do Código Tributário Nacional, já com base na doutrina de Seabra Fagundes, defendia tratar-se de ato administrativo. Algum tempo depois, entretanto, mudou de posicionamento passando a admitir que o lançamento poderia ser constituído por uma série de atos administrativos (1954, p.63-64).

BALEEIRO (1974, p.443), embora admita a tese procedimental do lançamento, ao comentar o Código Tributário Nacional, expressava a posição segundo a qual "é o ato administrativo de competência vinculada (...)".

CANTO (1964, p.171) define lançamento como "o ato através do qual se procede à verificação da ocorrência do fato gerador do imposto, à respectiva avaliação e consequente criação do débito fiscal individualizado".

Para ATALIBA (1969, p.277) o lançamento é ato declaratório que conferiria liquidez ao crédito. Nesse sentido também é a orientação de BORGES (1981, p. 103-104), ao distinguir a norma individual, expedida com $\mathrm{o}$ ato de lançamento, do procedimento administrativo que prepara a sua expedição.

Em sentido contrário, temos o magistério de BECKER (2007, p.325), de DÓRIA (1968, p.321-322) e de NOGUEIRA (1973, p.32-33) que adotam a concepção de que o lançamento tributário seria um procedimento.

\section{DA IMPOSSIBILIDADE DE REVOGAÇÃO DO LANÇA- MENTO TRIBUTÁRIO}

Como já exposto, o instituto lançamento tributário é um ato jurídico administrativo. Por se tratar de ato administrativo sua validade poderá ser objeto de contestações, a fim de se verificar se a atitude tomada pelo Estado está em conformidade com o ordenamento jurídico brasileiro.

Antes de adentrar propriamente nas invalidades ocorridas no lançamento tributário, faz-se necessário tecer alguns esclarecimentos acerca da revogação, que retrata uma das formas de modificação de um ato administrativo.

Gasparini (2011, p.156) define revogação 
“[...] como sendo a retirada, parcial ou total, de um ato administrativo válido e eficaz do ordenamento jurídico, mediante outro ato administrativo, por motivo de conveniência ou oportunidade, respeitados os efeitos produzidos".

A revogação ocorre no momento em que a Administração Pública determina a inconveniência ou inoportunidade de um ato perfeitamente válido para o interesse público. Portanto, "consiste no desfazimento do ato anterior" (JUSTEN FILHO, 2010, p.417).

Pelo fato de a revogação retirar um ato completamente válido do ordenamento jurídico, "o ato revogador tem sempre eficácia ex nunc" (MELLO, 2010, p.454). Assim, pode-se afirmar que a revogação possui efeito prospectivo, não abrangendo o passado.

É importante enfatizar que o ato administrativo de revogação é, em sua essência, discricionário, ou seja,

“[...] a lei deixa certa margem de liberdade de decisão diante do caso concreto, de tal modo que a autoridade poderá optar por uma dentre várias soluções possíveis, todas válidas perante o direito. Nesses casos, o poder da Administração é discricionário, porque a adoção de uma ou outra solução é feita segundo critérios de oportunidade, conveniência, justiça, equidade, próprios da autoridade, porque não definidos pelo legislador (DI PIETRO, 2012,p.219)".

No entanto, a revogação jamais será plenamente discricionária, eis que o administrador, por maior que seja a liberdade lhe conferida, deve agir nos estritos ditames legais.

Ocorre, em algumas situações, que a Administração Pública não pode alterar o conteúdo de um ato administrativo arguindo conveniência ou oportunidade; trata-se de limitações ao poder revogatório.

Alexandrino e Paulo (2010, p.482) demonstram de forma clara e sucinta os casos de incapacidade de revogação:

\section{“[...]}

a) os atos consumados, que já exauriram seus efeitos (a impossibilidade de revoga-los decorre de uma questão lógica, uma vez que, sendo a revogação prospectiva, ex nunc, não faz sentido revogar um ato que não tem mais nenhum efeito a produzir);

$[\ldots]$ 
b) os atos vinculados, porque não comportam juízo de oportunidade e conveniência;

[...]

c) os atos que já geraram direitos adquiridos, gravados por garantia constitucional (CF, art. $5^{\circ}, \mathrm{XXXVI)}$; deveras, se nem a lei pode prejudicar um direito adquirido, muito menos o poderia um juízo de conveniência ou oportunidade administrativa;

d) os atos que integram um procedimento, porque, sendo o procedimento administrativo uma sucessão ordenada de atos, a cada ato praticado passase a uma nova etapa do procedimento, ocorrendo a preclusão administrativa relativamente à etapa anterior, ou seja, torna-se incabível uma nova apreciação do ato anterior quanto ao seu mérito".

Merece destaque o contido na alínea "c". Como se sabe, ato vinculado é aquele que o administrador se encontra diante de situações que comportam solução única anteriormente prevista por lei.

Gasparine (2011, p. 148) enfatiza que

“[...] Vinculados são os atos administrativos praticados conforme o único comportamento que a lei prescreve à Administração Pública. A lei prescreve, em princípio, se, quando e como deve a Administração Pública agir ou decidir. A vontade da lei só estará satisfeita com esse comportamento, já que não permite à Administração Pública qualquer outro. Esses atos decorrem do exercício de uma atribuição vinculada ou, como prefere boa parte dos autores, do desempenho do poder vinculado, em cuja prática a Administração Pública não tem qualquer margem de liberdade".

No tocante ao lançamento tributário, viu-se que este é um ato administrativo vinculado que busca

"declarar formalmente a ocorrência do fato gerador, definir os elementos materiais da obrigação surgida (alíquota e base de cálculo), calcular o montante devido, identificar o respectivo sujeito passivo, com o fito de possibilidade que contra este seja feita a cobrança do tributo ou da penalidade pecuniária" (ALEXANDRE, 2010, p.365).

Assim, o administrador público deverá agir sem atitude alguma de pessoalidade e/ou liberdade (conveniência e oportunidade), apenas se pautando nos preceitos legais lhe impostos, tendo em vista que o lançamento é um ato 
jurídico administrativo vinculado. Cite-se que essa vinculação da Administração Publica decorre do fato de o lançamento constituir um crédito tributário, dotado de exigibilidade, certeza e liquidez, o qual expressa a abundância de poder da autoridade fiscal na instituição de receitas públicas.

Nesse sentido, Derzi (2000, p. 809) afirma que

"A modificação de um ato administrativo, na esfera administrativa, poderá ser feita por meio de revogação ou anulação. Mas a revogação supõe que a Administração desfaça ou refaça o ato, por iniciativa própria, fundada em razões de conveniência e oportunidade. Não obstante, como o lançamento é ato administrativo plenamente vinculado (arts. $3^{\circ}$ e 142 , parágrafo único), não pode ser revogado, por motivo de conveniência ou oportunidade, inexistindo margem de discricionariedade administrativa. Portanto, a sua revisão não poderá ser levada a cabo através de revogação. Sendo o lançamento defeituoso, por desrespeito aos requisitos e pressupostos legais que ditam o critério de validade a ser observado, cabe à Administração apenas anulá-lo em decorrência da ilegitimidade, do vício."

Logo, verifica-se que a revogação é uma faculdade da Administração Pública que consiste na modificação de um ato administrativo com fulcro na conveniência ou oportunidade do interesse público. O referido instituto não é admitido no lançamento tributário por se tratar este de um ato administrativo vinculado, o qual é tido por válido até prova em contrário capaz de ensejar sua alteração apenas no que se refere às invalidades (anulação ou nulidade).

\section{REGIME JURÍDICO DO ATO ADMINISTRATIVO DO LANÇAMENTO TRIBUTÁRIO: NULIDADE E ANULABILIDADE}

O lançamento tributário, como já foi apresentado, é um ato administrativo vinculado, que tem por objetivo "dar ciência ao sujeito passivo, a fim de que este fique adstrito a, no prazo assinalado, satisfazer o direito do credor, sob pena de serem desencadeados os procedimentos tendentes à cobrança judicial" (AMARO, 2007, p.333).

Na condição de ato, o lançamento tributário se sujeita às lições previstas no ramo do Direito Administrativo, especificamente no que concerne à teoria dos atos administrativos. 
Dessa forma, quando o administrador público agir, por uma ou outra razão, em desacordo com os ditames previstos no ordenamento jurídico no momento da realização do lançamento tributário, restará configurado um vício, denominado invalidação, cujo conceito é dado pela doutrina administrativista.

Conforme MELLO (2010, p.462), “invalidação é a supressão de um ato administrativo ou da relação jurídica dele nascida, por haverem sido produzidas em desconformidade com a ordem jurídica”.

De acordo com DIAS (2005, p.338)

"No Direito Público, no que diz respeito ao ato administrativo, não há uma classificação legal das nulidades com todas as suas consequências, as regras para desfazimento do ato, os prazos e os legitimados.

A despeito disso, a doutrina administrativista produziu teorias a respeito da nulidade dos atos administrativos, uma vez que, em razão do princípio da legalidade que norteia a Administração Pública, não é admissível a manutenção de atos praticados com determinados vícios".

Cumpre esclarecer que não há um posicionamento uníssono na doutrina quanto à caracterização da invalidade. Alguns entendem que, no Direito Administrativo, ato ilegítimo é nulo, outros afirmam existir a diferenciação de atos nulos e anuláveis, e existem aqueles que aderem também a espécie de atos inexistentes.

Para análise das invalidades no lançamento tributário será adotado, no presente trabalho, a tradicional diferenciação entre atos nulos e anuláveis. Porém, é importante destacar que essa distinção não significa existir níveis de invalidação, pois

"Ato algum em Direito é mais inválido do que outro. Todavia, [...] a ordem normativa pode repelir com intensidade variável atos praticados em desobediência às disposições jurídicas, estabelecendo, destarte, uma gradação no repúdio a eles (MELLO, 2010, p.461).

Assim, conceitua-se ato nulo como sendo aquele que não se admite o saneamento ou convalidação, "pois se o mesmo conteúdo fosse novamente produzido, seria reproduzida a invalidade anterior", e ato anulável como "os que podem ser praticados sem vícios" (DI PIETRO, 2012, p.252).

Ressalta-se, ainda, que poderão invalidar os atos administrativos não somente a Administração Pública, mas também o Poder Judiciário. 


\subsection{A NULIDADE NO LANÇAMENTO TRIBUTÁRIO}

O lançamento tributário pode ter sua validade contestada, eis que se trata de um ato administrativo que formaliza a obrigação da Administração Pública em exigir do contribuinte o pagamento do tributo devido.

Inicialmente, é preciso distinguir dois institutos apresentados pela doutrina, a saber, erro de direito e erro de fato.

De acordo com os ensinamentos de MACHADO (2.2007, p.203),

"Há erro de direito quando o lançamento é feito ilegalmente, em virtude de ignorância ou errada compreensão da lei. O lançamento, vale dizer, a decisão da autoridade administrativa, situa-se, neste caso, fora da moldura ou quadro de interpretação que a Ciência do Direito oferece"

Para ALEXANDRE (2010, p.380), "erro de fato se refere ao incorreto enquadramento das circunstâncias objetivas que não dependem de interpretação normativa para sua verificação".

Como muito bem explica DIAS (2005, p.345),

“[...] para que o lançamento possa produzir os seus efeitos, nele deverão estar presentes todos os seus elementos e pressupostos. Atendido tais requisitos o lançamento será ato perfeito e acabado, produzindo efeitos jurídicos, ainda que eivados de vícios e imperfeições. [...] a ausência ou deficiência dos requisitos pode levar à invalidação do ato do lançamento, com consequências distintas em razão da natureza da imperfeição".

No atual ponto será abordada a questão da nulidade do ato administrativo realizado no lançamento tributário, sendo primeiramente necessário estabelecer quando isso ocorrerá.

Conforme CARVALHO (2011, p.496),

"O ato administrativo de lançamento será declarado nulo, de pleno direito, se o motivo nele inscrito - a ocorrência de fato jurídico tributário, por exemplo - inexistiu. [...] Para a nulidade se requer vício profundo, que comprometa visceralmente $\mathrm{o}$ ato administrativo."

Uma importante circunstância que acarreta a nulidade do lançamento tributário é a presença de erros de direito. 
De acordo com o acima exposto, o erro de direito é aquele "decorrente da escolha equivocada de um módulo normativo inservível ou não mais aplicável à regência da questão que estivesse sendo juridicamente considerada" (COÊLHO, 2007, p.764).

Para demonstrar a ocorrência de erros de direito quando do lançamento tributário, será utilizada a doutrina contemporânea de CARVALHO (2011, p.493).

Como primeiro exemplo, pode-se apontar o fato de uma autoridade administrativa exigir Imposto sobre a Propriedade Territorial Rural (ITR) do arrendatário, ao invés de determinar que o proprietário do imóvel rural cumpra o dever de recolher o ITR. Nesse caso, ter-se-á erro de direito quanto ao elemento subjetivo, mais especificamente sobre o sujeito passivo da regra-matriz de incidência fiscal.

De igual forma, será configurado erro de direito quando, por exemplo, a base de cálculo de um imposto é o valor da operação e o valor do frete, e o agente público, ao lavrar o ato de lançamento, interpreta a previsão legal e registra como base de cálculo somente o valor da operação. Logo, caracterizado estará erro de direito, devido à dissonância entre o enunciado do consequente da norma individual e concreta e o enunciado do consequente da regra-matriz de incidência fiscal, ambos no que diz respeito ao elemento/critério quantitativo.

Assim, sempre que for demonstrado algum problema ou equívoco de interpretação da norma jurídica por parte da autoridade administrativa no lançamento tributário, configurando um desacerto normativo, haverá erro de direito.

Este erro enseja a nulidade do ato administrativo, pois é incapaz de ser alterado, conforme prevê o art. art. 146 do CTN, o qual visa proteger o princípio da segurança jurídica e o da não surpresa, garantindo que as mudanças de critérios jurídicos utilizados pelo Fisco no lançamento tributário somente terão efeitos aos casos futuros.

Nesse sentido, COÊLHO (2007, p.761) afirma que “o lançamento tributário já definitivamente constituído é irreversível pela Administração em caso de erro de direito ou de valoração jurídica dos fatos".

Logo, restando caracterizada alteração no critério jurídico do lançamento tributário, incorrerá o fisco em erro de direito, o qual não permite a revisão ou alteração do lançamento, mas apenas a declaração de nulidade do ato.

Para ilustrar, destaca-se a ementa da decisão proferida no recurso especial nº 2011/0309352-3 interposto ao Superior Tribunal de Justiça: 
"TRIBUTÁRIOE PROCESSUAL CIVIL.APELAÇÕES CÍVEIS. EMBARGOS À EXECUÇÃO FISCAL. ISS. PRELIMINAR: TRANSFERÊNCIA PARAO MÉRITO. MÉRITO: NÃO PRODUÇÃO DE PROVA PERICIAL. CERCEAMENTO DO DIREITO DE DEFESA. INOCORRÊNCIA. QUESTÃO UNICAMENTE DE DIREITO. DECADÊNCIA. LANÇAMENTO DE OFÍCIO SUPLETIVO DE LANÇAMENTO POR HOMOLOGAÇÃO.AUSÊNCIADE DECLARAÇÃO E DE PAGAMENTO. APLICAÇÃO DA REGRA DO ART. 173, I, DO CTN. MOMENTO DO FATO GERADOR. SITUAÇÃO DE FATO. ART. 116, I, DOCTN. REJEIÇÃO. ALTERAÇÃO DOCRITÉRIOJURÍDICO. OCORRÊNCIA. NULIDADE.ART. 146 DO CTN". [...]

4. A consideração pela autoridade fiscal de que um determinado fato não é tributável e, em momento posterior, no mesmo processo de lançamento fiscal, adiciona-se outros requisitos para que esse fato seja considerado não tributável, configura modificação do critério jurídico, vedada pelo art. 146, do CTN.

5. Apelo da Koch Petróleo do Brasil Ltda. conhecido e provido. Apelo do Município de Areia Branca prejudicado. é o caso (REsp n ${ }^{\circ}$ 2011/0309352-3, Relator Ministro HUMBERTO MARTINS, de 17/02/2012). (destaques acrescentados).

Ademais, semelhante julgamento se deu no recurso especial 2010/ 0170845-3:

RECURSO ESPECIAL. TRIBUTÁRIO, PROCESSUAL CIVIL E PROCESSO ADMINISTRATIVO FISCAL. ART. 535 DO CPC. AUSÊNCIA DE CONTRADIÇÃO OU OMISSÃO. ARTS. 594 DO CCE 110 DO CTN. OFENSA NÃO DEMONSTRADA. AÇÃO ANULATÓRIA DE LANÇAMENTO TRIBUTÁRIO. ISSQN. TRANSMISSÃO TELEVISA, LICENCIAMENTODE PRODUTOS E PROPAGANDA ESTÁTICA. DIREITO DE USO E EXPLORAÇÃO DE IMAGEM DE CLUBE DE FUTEBOL, COM O QUALA RECORRENTE FIRMARA CONTRATOS DE LICENÇA PARA USO DE MARCA E DE EXPLORAÇÃO DE ESPAÇOS PUBLICITÁRIOS. ATIVIDADES EQUIPARADAS PELAAUTORIDADE FISCALÀ LOCAÇÃO DE BENS MÓVEIS, QUANDO DA AUTUAÇÃO. MODIFICAÇÃO DO CRITÉRIO JURÍDICO ADOTADO PELO FISCO NO LANÇAMENTO PELOJUDICIÁRIO, PARAINCLUIRASATIVIDADES DAEMPRESAEM OUTRO ITEM DA LISTA DE SERVIÇOS. ERRO DE DIREITO. INADMISSIBILIDADE. ARTS. 142 E 146 DO CTN. APLICABILIDADE DA SÚMULA VINCULANTE 31/STF. RECURSO ESPECIAL 
PARCIALMENTE CONHECIDO E, NESSA PARTE, PARCIALMENTE PROVIDO, PARACANCELAR OAUTODEINFRAÇÃOAPENAS QUANTO À COBRANÇA DE ISSQN E MULTADECORRENTES DAS ATIVIDADES EQUIPARADAS À LOCAÇÃO DE BENS MÓVEIS, SEM PREJUÍZO DA RENOVAÇÃO DAAUTUAÇÃO, EM FORMAREGULAR, SEFOR OCASO. [...] 6. No caso concreto, o que se constata é que a autoridade administrativa reconheceu o fato gerador concreto para fins de incidência do ISSQN como sendo uma locação de bens móveis, embora, essa não seja a real atividade desenvolvida pela empresa, como bem captaram o Julgador Singular e o Tribunal Estadual; todavia, não cabe ao Judiciário substituir a Autoridade Fiscal, para dar outra qualificação jurídica aos fatos por ela já analisados, corrigindo, dessa forma, típico erro de direito do lançamento, pois isso afronta o princípio da legalidade, do qual o princípio da tipicidade fechada é corolário, bem como o da segurança jurídica.

7. A Primeira Seção desta Corte encampou a Súmula 227/TFR, segundo a qual a mudança de critério jurídico adotado pelo Fisco não autoriza a revisão de lançamento: REsp. 1.130.545/RJ, Rel. Min. LUIZ FUX, DJe 22/02/ 2011, julgado sob o regime do art. 543-C do CPC.

8. Se a Autoridade Fiscal enquadrou a atividade da recorrente como locação de bens móveis, e o STF já decidiu que sobre ela não incide ISS (Súmula Vinculante 31), mostra-se ilegal a modificação judicial desse critério jurídico, para fins de validar o lançamento efetuado. (REsp n ${ }^{\circ}$ 2010/01708453, Relator Ministro NAPOLEÃO NUNES MAIA FILHO, de 27/03/2012). (destaques acrescentados).

É importante mencionar que o Superior Tribunal de Justiça tem entendimento reiterado de que não é possível a revisão do lançamento de ofício em hipótese em que se configurou erro de direito, de acordo com o teor da Súmula 227 do extinto Tribunal Federal de Recursos (TFR): 'A mudança de critério jurídico adotado pelo Fisco não autoriza a revisão de lançamento. ‘

Como ensina ROSA JÚNIOR (2005, p.594),

“[...] o objetivo do legislador ao estabelecer a norma contida no art. 146 do CTN foi vedar a alteração do lançamento quando a Administração no lançamento anterior praticou erro de direito, adotando critério jurídico equivocado, ainda que a nova interpretação decorra de decisão administrativa ou judicial. (...) Tal mudança de critérios jurídicos não pode alcançar fatos geradores já ocorridos para maior segurança do contribuinte, e porque um dos efeitos mais importantes do fato gerador é fixar o regime jurídico da tributação". 
Destarte, conclui-se que é integralmente nulo o ato da autoridade administrativa alterar um lançamento tributário diante da presença de um erro de direito, ou seja, erro na aplicação ou interpretação da norma jurídica, devido à proibição prevista no art. 146 do CTN, que reiteradamente enseja decisões jurisprudenciais nesse sentido.

\subsection{AANULABILIDADE NO LANÇAMENTO TRIBUTÁRIO}

$\mathrm{O}$ art. 173 do CTN dispõe que é permitido à Administração Pública realizar a anulação, por vício formal, de um lançamento realizado.

Por vício formal entende-se erro de fato, ou seja, uma "circunstância jurídica delineada pela inadequação do 'conceito do fato' ao estado de coisas (fato concreto) a que se dirige" (SANTI, 2001, p.263).

Da análise do supracitado dispositivo legal, resta claro que o lançamento tributário será considerado ato anulável quando nele contiver um vício formal (erro de fato).

É importante mencionar que atos anuláveis são aqueles que podem ser convalidados, isto é, aqueles que podem ter sua falha suprida após o decurso de certo lapso temporal.

Conforme nos ensina MELLO (2010, p.478), são anuláveis "os atos que podem ser repraticados sem vício".

Dessa forma, diante da configuração de erro de fato no lançamento tributário, o procedimento a ser tomado pela autoridade administrativa é o de revisar o lançamento realizado e proceder à sua correção, observando o prazo decadencial previsto no art. 173 do CTN.

Para melhor ilustrar a caracterização da revisão de um lançamento tributário decorrente de erro de fato, citem-se duas ocorrências apresentadas pela doutrina (CARVALHO, 2011, p.493). Veja.

Devido a um engano da Administração, esta registrou que um fato ocorreu no Município $\mathrm{M}^{\prime}$, quando na verdade, tinha ocorrido no Município M. Após constatado o equívoco acerca do elemento espacial, deverá o servidor responsável proceder a revisão do lançamento realizado, de forma a sanar os vícios apurados.

Outro exemplo se pauta no registro de uma base de cálculo do Imposto Territorial e Predial Urbano (IPTU) de um contribuinte, de acordo com o imóvel de seu vizinho. Nesse caso, comprovada a inversão da análise imobiliária, o erro de fato verificado no elemento quantitativo da norma 
tributária ensejará o refazimento do lançamento tributário com a devida correção dos vícios.

A fim de demonstrar a recente aplicação jurisprudencial acerca do tema, é importante fazer alusão ao julgamento do agravo regimental interposto no agravo de recurso especial 1130545/RJ ao Superior Tribunal de Justiça, do qual segue a ementa:

PROCESSO CIVIL. TRIBUTÁRIO. IPTU. DIFERENÇA NO PADRÃO DE ACABAMENTO DO IMÓVEL. REVISÃO DO LANÇAMENTO. POSSIBILIDADE. ERRO DE FATO. CARACTERIZAÇÃO. ART. 149, INCISO VIII, DO CTN. RECURSO REPETITIVO JULGADO. RESP 1130545/ RJ.

1. Trata-se de recurso especial interposto contra acórdão proferido pelo Tribunal de Justiça do Estado de Minas Gerais que decidiu pela legalidade da revisão de lançamento do IPTU relativo ao exercício de 1998, com fundamento no art. 149, inciso VIII, do CTN.

2. O Tribunal a quo, ao analisar acerca da revisão de lançamento do IPTU, decidiu que “(...) razão não assiste ao apelante, pois o desacerto no cálculo do IPTU decorrente da apuração do padrão de acabamento do imóvel configura erro de fato, podendo o mesmo ser corrigido, de oficio, conforme a regra dos artigos $145 \mathrm{c} / \mathrm{c}$ 149, VIII, ambos do Código Tributário Nacional, sem que tal fato implique violação ao princípio da irretroatividade da exação (...)".

3. Pela leitura do trecho acima, verifica-se que o lançamento original reportouse a um padrão de acabamento diferente da realidade, o que ensejou posterior retificação dos dados, hipótese que se enquadra no disposto no artigo 149, inciso VIII, do CTN, razão pela qual conclui-se pela higidez da revisão do lançamento tributário.

4. Dessa forma, como o lançamento complementar decorreu de um verdadeiro erro de fato, qual seja, erro no padrão do acabamento do imóvel, possível a revisão do lançamento tributário (artigo 149, inciso VIII, do CTN).

5. No REsp 1130545/RJ, Rel. Ministro LUIZ FUX, PRIMEIRA SEÇÃO, julgado em 09/08/2010, DJe 22/02/2011, submetido ao Colegiado pelo regime da Lei ${ }^{\circ}$ 11.672/08 (Lei dos Recursos Repetitivos), que introduziu o art. 543-C do CPC, reafirmou-se o posicionamento acima exposto

6. Agravo regimental não provido. (REsp no $1130545 / \mathrm{RJ}$, Relator Ministro MAURO CAMPBELL MARQUES, DJ de 20/10/2011). (destaques acrescentados). 
Do mesmo modo,

PROCESSUAL CIVIL. TRIBUTÁRIO. Recurso Especial representativo de controvérsia (art. 543-C, $\S 1^{\circ}$, do CPC). AUTO DE INFRAÇÃO LAVRADO COM BASE EM DECLARAÇÃO EMITIDA COM ERRO DE FATO NOTICIADO AO FISCO E NÃO CORRIGIDO. VÍCIO QUE MACULAA POSTERIOR CONFISSÃO DE DÉBITOS PARA EFEITO DE PARCELAMENTO. POSSIBILIDADE DE REVISÃO JUDICIAL.

1. A Administração Tributária tem o poder/dever de revisar de ofício o lançamento quando se comprove erro de fato quanto a qualquer elemento definido na legislação tributária como sendo de declaração obrigatória (art. 145, III, c/c art. 149, IV, do CTN).

2. A este poder/dever corresponde o direito do contribuinte de retificar e ver retificada pelo Fisco a informação fornecida com erro de fato, quando dessa retificação resultar a redução do tributo devido.

3. Caso em que a Administração Tributária Municipal, ao invés de corrigir o erro de ofício, ou a pedido do administrado, como era o seu dever, optou pela lavratura de cinco autos de infração eivados de nulidade, o que forçou o contribuinte a confessar o débito e pedir parcelamento diante da necessidade premente de obtenção de certidão negativa.

[...] (REsp n ${ }^{\circ}$ 2009/0153316-0, Relator Ministro LUIZ FUX, DJ de 13/10/2010). (destaques acrescentados).

Logo, partilhamos do seguinte entendimento: chegando ao conhecimento do administrador público que um lançamento tributário possui vício formal (erro de fato), aquele deverá proceder à correção, à revisão do lançamento efetuado, de modo a refazer o ato administrativo sem erros.

Isto é possível, pois o lançamento tributário é um ato administrativo que, na presença de erro formal, configura ato anulável, o qual é passível de convalidação, a saber, o saneamento de um ato inválido, através da feitura de outro ato administrativo que o corrija.

Por fim, finaliza-se o presente trabalho afirmando que tanto o erro de fato quanto o erro de direito estão compreendidos nas invalidades do lançamento tributário; enquanto o erro de fato (aquele que se trata de dado objetivo equivocado), enseja a convalidação do lançamento realizado pelo administrador público, o erro de direito acarreta a nulidade do lançamento, eis que se pauta em lançamento ilegal por questões de equívocos ou dissonâncias jurídicas que não podem ser toleradas pelo conjunto de normas brasileiras. 


\section{CONSIDERAÇÕES FINAIS}

O trabalho teve como escopo abordar as invalidades do ato administrativo no lançamento tributário.

Através de pesquisa sobre o tema, inicialmente, apresentou-se os diversos conceitos de lançamento tributário exibidos pela doutrina brasileira, bem como se ratificou a eficácia declaratória do referido instituto.

O presente artigo demonstrou que o lançamento tributário é um ato jurídico administrativo constitutivo e vinculado praticado por agente público no exercício de função administrativa visando aplicar a lei com a observância de certos procedimentos; e, por se tratar de ato administrativo, aplicou-se ao lançamento a teoria geral dos atos administrativos.

Restou comprovada a impossibilidade de revogação do lançamento tributário, pois este é um ato vinculado, incompatível com o poder discricionário da Administração Pública.

E, por fim, estudou-se de modo afinco o instituto da invalidação do lançamento tributário, o qual ensejou as seguintes conclusões: 1 - o erro de fato se trata de um vício formal que torna o lançamento tributário anulável, ou seja, passível de ser convalidado dentro do prazo decadencial previsto no art. 173 do Código Tributário Nacional, competindo ao administrador público revisar o lançamento anteriormente efetuado, sanando o vício; 2 - o erro de direito contido no lançamento tributário não pode ser corrigido ou alterado, eis que se trata de erro na aplicação da norma jurídica ou de mudança de critério jurídico utilizado pelo Fisco, cabendo, apenas, a declaração de nulidade do referido ato pela autoridade competente.

\section{REFERÊNCIAS}

ALEXANDRE, Ricardo. Direito Tributário Esquematizado. 4.ed. Rio de Janeiro: Forense; São Paulo: Método, 2010.

ALEXANDRINO, Marcelo; PAULO, Vicente. Direito Administrativo Descomplicado. 18. ed. Rio de Janeiro: Forense; São Paulo: Método, 2010.

AMARO, Luciano. Curso de direito tributário. 19. ed. São Paulo: Saraiva, 2007. 
. Direito Tributário Brasileiro. 14 ed. São Paulo: Saraiva, 2007.

ATALIBA, Geraldo. Hipótese de incidência tributária. 2. ed. Revista dos Tribunais, 1975.

BALEEIRO, Aliomar. Limitações constitucionais ao poder de tributar. 4. ed. Rio de Janeiro: Forense, 1974.

BECKER, Alfredo Augusto. Teoria geral do direito tributário.

4. ed. Saraiva, 2007.

BORGES, José Souto Maior. Lançamento tributário, in Tratado de direito tributário. v. 4.Rio de Janeiro: Forense, 1981.

CANTO, Gilberto de Ulhôa. Temas de direito tributário. v.1. Alba, 1964.

CARVALHO, Paulo de Barros. Curso de direito tributário. 23.ed. São Paulo: Saraiva, 2011.

CARVALHO FILHO, José dos Santos. Manual de direito administrativo. Rio de Janeiro: Lumen Juris, 2009.

COÊLHO, Sacha Calmon Navarro. Curso de Direito Tributário Brasileiro. 9. ed. Rio de Janeiro: Forense, 2007.

DE MELlO, Celso Antônio Bandeira. Curso de Direito Administrativo. 22 ed. São Paulo: Malheiros, 2007.

DERZI, Misabel Abreu Machado. Direito Tributário Brasileiro. 11. ed. Rio de Janeiro: Forense, 2000.

DI PIETRO, Maria Sylvia Zanella. Direito Administrativo. 25. ed. São Paulo: Atlas, 2010.

FALCÃO, Amílcar de Araújo. Fato gerador da obrigação tributária. 2. ed. Revista dos Tribunais. 
FÜHRER, Maximilianus Cláudio Américo; FÜHRER, Maximiliano Roberto Ernesto. Resumo de Direito Tributário. 9. ed. São Paulo: Malheiros, 2001.

GASPARINI, Diógenes. Direito Administrativo. 16. ed. São Paulo: Saraiva, 2011.

JUSTEN FILHO, Marçal. Curso de Direito Administrativo. 7.ed. Belo Horizonte: Fórum, 2011.

. Curso de direito administrativo. 6. ed. Belo Horizonte:

Fórum, 2010.

MACHADO, Hugo de Brito. Curso de Direito Tributário. 32.ed. São Paulo: Malheiros, 2011.

. Curso de Direito Tributário. 28. ed. São Paulo, Malheiros, 2007.

MEIRELLES, Hely Lopes. Direito administrativo brasileiro. 27. ed.

São Paulo: Malheiros, 2002.

MELLO, Celso Antonio Bandeira de. Curso de Direito Administrativo. 27. ed. São Paulo: Malheiros, 2010.

NOGUEIRA, Ruy Barbosa. Curso de direito tributário. 5. ed. Saraiva, 1980.

. Teoria do lançamento tributário. Resenha Tributária, 1973.

ROSA JUNIOR, Luiz Emygdio F. da. Manual de direito financeiro e de direito tributário. 18.ed. Rio de Janeiro: Renovar, 2005.

SAMPAIO DÓRIA, Antônio Roberto. Da lei tributária no tempo. São Paulo: Obelisco, 1968.

SANTI, Eurico Marcos Diniz de. Lançamento tributário. 2.ed. São Paulo: Max Limonad, 2001. 
SOUZA, Rubens Gomes de. Compêndios de legislação tributária. 2.ed. Rio de Janeiro: Ed. Financeiras, 1954. . Estudos de direito tributário. São Paulo: Saraiva, 1950.

TORRES, Heleno Taveira et al. (coordenação). Direito Tributário e Processo Administrativo Aplicados. São Paulo: Quartier Latin, 2005.

Recebido em: 27/11/2012 Aprovado para publicação em: 08/04/2013

Como citar: CAMPOS, Patrícia Toledo de; BRUNIERA, Reinaldo de Oliveira. As Invalidades do Ato Administrativo no Lançamento Tributário. Revista do Direito Público, Londrina, v.8, n.1, p.115-136, mai.2013. DOI: 10.5433/1980-511X.2013v8n1p115. 